\title{
YSZ-Based Oxygen Sensors and the Use of Nanomaterials: A Review from Classical Models to Current Trends
}

\author{
Carlos López-Gándara, ${ }^{1,2}$ Francisco M. Ramos, ${ }^{1}$ and Albert Cirera ${ }^{2}$ \\ ${ }^{1}$ FAE-Francisco Albero S.A., R\&D Advanced Materials, Rafael Barradas 19, 08908 L'Hospitalet de Llobregat, Barcelona, Spain \\ ${ }^{2}$ MIND/IN2UB, Electronics Department, Universitat de Barcelona, Martí i Franquès 1, 08028 Barcelona, Spain
}

Correspondence should be addressed to Albert Cirera, acirera@ub.edu

Received 1 January 2009; Revised 1 June 2009; Accepted 23 July 2009

Recommended by Giorgio Sberveglieri

This work reviews physicochemical models on the operation and the response of potentiometric oxygen gas sensors based on ionconducting electrolytes. The aim for describing the electric response and some properties like response time, ionic conductivity, catalytic activity, or gas selectivity of these devices has led to the development of some models in the last decades. These models have provided information on relations between the response of the sensors, their design and fabrications process, and some morphological properties, like grain size of the electrolyte, diffusion on protective layers, or density of three-phase boundary points in the measuring electrodes. Current trends on improving catalysis, gas selectivity, and activation energy for ion conducting by using nanomaterials are described as well.

Copyright (C) 2009 Carlos López-Gándara et al. This is an open access article distributed under the Creative Commons Attribution License, which permits unrestricted use, distribution, and reproduction in any medium, provided the original work is properly cited.

\section{Introduction}

Chemical gas sensors have been widely developed in the last decades for different purposes. Oxygen sensors, which have been the most studied devices in this area, have been appropriate devices for combustion control in automotive applications $[1,2]$. Also, most of the different electrochemical gas sensing devices have the same phenomenology and working principles, which are almost identical to the ones of typical oxygen sensors. Therefore, understanding the oxygen sensing mechanisms leads to a vast knowledge on many other similar gas sensing devices.

Oxygen sensing can be achieved by means of different working principles: among others, electrochemical, pumping gauge, or resistive oxygen sensors have been developed in the past. One of the most usual systems is the electrochemical oxygen sensor, based on ceramic ion-conducting electrolytes. Moreover, current trends in the development of these sensors, such as the implementation of nanomaterials to improve sensing characteristics or promoting gas selectivity in nonequilibrated gas mixtures, demand a precise knowledge on which parameters determine the sensors behavior. The complexity of these systems and the difficulty to establish all the processes involved in their normal operation mode has lead to different physical and physicochemical models across the years.

This work is focused on reviewing models on ionconducting potentiometric oxygen sensors. Their static and dynamic response is modeled. Some concerns on the electrolyte characteristics are presented, and models of the electrode properties are considered as well. A special emphasis is made on the use of nanomaterials in the electrodes and electrolytes. Selective sensing in these devices thanks to the mixed potential is also commented.

\section{Background}

2.1. Structure of the Sensor. Potentiometric sensing devices based on ion-conducting ceramics usually present the same basic structure (Figure 1):

Measured gas/Metal/Ion conductor/Metal/Reference gas.

A ceramic ion-conducting electrolyte is covered by two catalytic active metals and is put in contact with two different atmospheres: the measuring one and a reference atmosphere whose composition is known (generally air). 


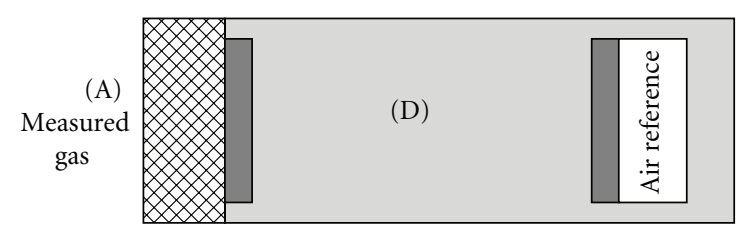

(B) (C)

(E) $(\mathrm{F})$

FIGURE 1: Schematic structure of a potentiometric planar oxygen sensor. (A) Measuring atmosphere. (B) Porous protective layer. This layer is optional as it prevents from electrode degradation and sometimes it improves the sensor response due to gas species diffusion. (C) Measuring electrode, catalytically active, generally made of platinum. (D) $\mathrm{O}_{2-}$ ion-conductive ceramic electrolyte. The most used electrolyte is $\mathrm{Y}_{2} \mathrm{O}_{3}$-doped $\mathrm{ZrO}_{2}$ (YSZ). (E) Reference electrode, in contact with (F) Air reference atmosphere. Some sensors have been occasionally described without a reference atmosphere. Also, a heating element (a dissipative low resistance) is optionally put in front of this sensor structure to achieve stable, high enough temperatures.

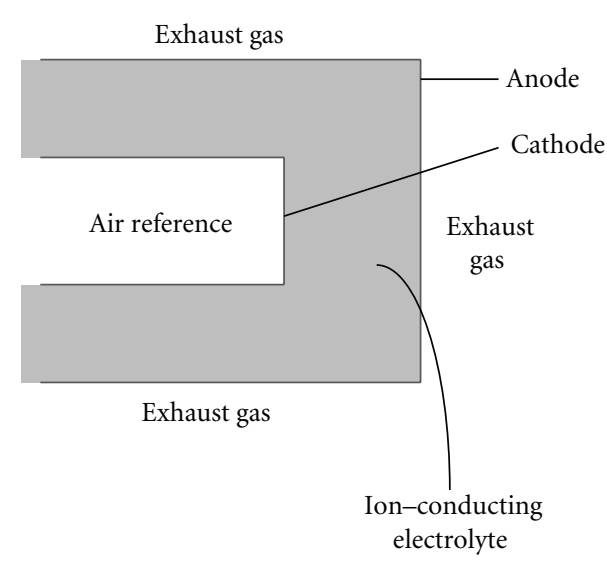

Figure 2: Schematic structure of a thimble-type potentiometric oxygen sensor.

In oxygen sensors, this structure consists in a $\mathrm{O}^{2-}$ conductor such as $\mathrm{Y}_{2} \mathrm{O}_{3}$-doped $\mathrm{ZrO}_{2}$ (YSZ) with platinum electrodes. Ion-conduction is thermally activated above 600 $650 \mathrm{~K}$ in this ceramic. Gas sensors can optionally include a dissipative resistance near the sensing cell as a heating element to reach a stable, high temperature. This is usual in gas sensors for automotive applications, such as lambda sensors. Also, a protective layer is sometimes put over the measuring electrode to prevent from corrosion or to avoid changing the catalyst properties as ageing the sensor.

When initially developed, oxygen sensors were thimbletype (Figure 2). Since the 1980s, these sensors were also designed in planar-type (see Figures 1 and 3). Although the planar structure requires lower size, lower power consumption for the heating element, and lower fabrication costs and enables better stability in the measurements, the physical principles governing the behavior of the sensors are essentially the same in both thimble and planar types. As will be shown in Section 2.3, some planar sensors work with no air reference in one of their electrodes.

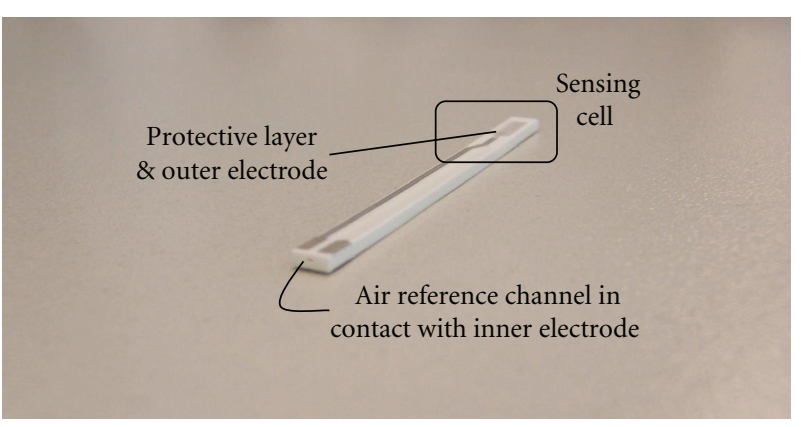

FIGURE 3: Image of a real commercial oxygen potentiometric sensor made of YSZ. The sensing cell consists in a Pt electrode exposed to the unknown gas, the ceramic electrolyte (YSZ), and another Pt electrode exposed to air via the reference channel, which is not in contact with the measured gas in the normal operation mode of the sensor. Also, a protective and diffusive layer is put over the measuring electrode. The layer is visually indistinguishable from the electrode.

The ceramic process for developing planar sensors requires techniques like tape casting, screen printing, piling up substrates, or ceramic sintering. Structural and electrochemical properties of the resulting devices are extremely dependent on the conditions these techniques have been carried out.

2.2. Response of the Sensor. When exposed to a certain gas mixture, an open circuit voltage $V_{\text {OC }}$ can be measured between the working and reference electrodes:

$$
V_{\mathrm{OC}}=\frac{k_{B} T}{4 e} \ln \frac{p_{\mathrm{O}_{2}, \mathrm{REF}}^{*}}{p_{\mathrm{O}_{2}}^{*}},
$$

where $k_{B}$ is Boltzmann's constant, $T$ is the temperature, $e$ the elementary charge, $p_{\mathrm{O}_{2}}^{*}, \mathrm{REF}$ is the oxygen's partial pressure in the reference gas (which corresponds to a $21 \% \mathrm{O}_{2}$ concentration in air), and $p_{\mathrm{O}_{2}}^{*}$ is the oxygen's partial pressure in the measuring gas. The term $k_{B} T / 4 e$ is frequently referred as $R T / 4 F$, which is exactly the same. This is the well-known Nernst equation.

According to (2), the electric response of the sensors would be a logarithmic dependence on $p_{\mathrm{O}_{2}}^{*}$, which does not seem a very sensitive response (see Figure 4 for a simple model of response to $\mathrm{O}_{2}-\mathrm{N}_{2}$ mixtures), with output voltages of some $\mathrm{mV}$ in front of concentrations of about 1\%-10\% $\mathrm{O}_{2}$ in $\mathrm{N}_{2}$. It can be seen that, at the typical temperatures of operation, the Nernst open circuit voltage would be near 1 volt if the relation $p_{\mathrm{O}_{2}, \mathrm{REF}}^{*} / p_{\mathrm{O}_{2}}^{*}$ was very high, that is, when oxygen's partial pressure in the air reference was several orders of magnitude higher than the oxygen's partial pressure in the measured gas (e.g., less than ppm of $\mathrm{O}_{2}$ in the measured gas). However, due to the presence of metal catalysts such as platinum in the electrodes, oxygen sensors may be sensitive to other gas species. For instance, reducing species such as $\mathrm{CO}$ and hydrocarbons, which may be present in the measured gas, can react with oxygen in the catalytically active Pt electrodes. Near the measuring electrodes, as the equilibrium concentration of oxygen may 


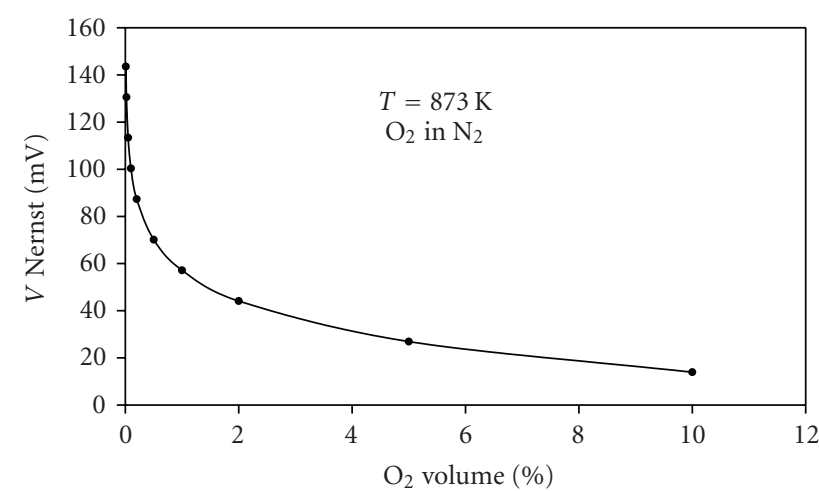

FIgURE 4: Modeled Nernstian response for an imaginary sensor with an air reference $\left(21 \% \mathrm{O}_{2}\right)$ according to (2), for oxygen concentrations in the range from $0.01 \%$ to $10 \%$ vol.

be extremely depleted after reacting with $\mathrm{CO}$ or HCs, the YSZ-based sensors can show high voltages (near 1V) when exposed to nonequilibrated mixtures containing reducing gases and oxygen. Platinum electrodes let $\mathrm{O}_{2}$ molecules react with the reducing species, causing a deep local decrease of $p_{\mathrm{O}_{2}}^{*}$ in their adsorption sites. Equation (2) is still valid, but only for the chemically equilibrated gas mixture near the Pt electrodes, and not for the $\mathrm{O}_{2}$ concentration in the nonequilibrated bulk gas. Therefore, the introduction of nonequilibrated reducing species may result in a voltage drop near 1 volt, and oxygen sensors can subsequently work also as reducing gas sensors. In other words, potentiometric oxygen sensors based on $\mathrm{O}^{2-}$ conduction are paradoxically more sensitive to the presence of reducing species than to oxygen. The presented structure (1) works as lambda sensors in automotive applications for combustion control and exhaust gas sensing.

In combustion engines, the parameter $\lambda$ is a signal on how close is the combustion of a mixture air/fuel to stoichiometric conditions [4]. $\lambda$ is defined as

$$
\lambda=\frac{\text { (volume of air/volume of fuel)(actual) }}{\text { (volume of air/volume of fuel)(stoichiometric) }} .
$$

A stoichiometric mixture corresponds to $\lambda=1$. Lean mixtures (excess of oxygen, air/fuel ratio higher than the stoichiometric air/fuel ratio) are characterized by $\lambda>1$, whereas rich mixtures (lack of oxygen, air/fuel ratio lower than the stoichiometric air/fuel ratio) are characterized by $\lambda<1$.

YSZ-based sensors can work as $\lambda$-sensors. Figure 5 shows a typical response for a lambda sensor exposed to several exhaust gases corresponding to different values of the parameter $\lambda$. In the lean region $(\lambda>1), \mathrm{O}_{2}$ concentration reaches $1 \%-3 \%$ in equilibrium. As said before, $V\left(\left[\mathrm{O}_{2}\right]\right)$ is in the order of tens of $\mathrm{mV}$ with a logarithmic dependence, not very sensitive to $p_{\mathrm{O}_{2}}^{*}$. In the rich region, the exhaust gas contains significant amounts of carbon monoxide and hydrocarbons, that is, reducing gases. This justifies the high open circuit voltage for $\lambda<1$. Near $\lambda=1$, there is an abrupt voltage drop due to the change from rich to lean conditions. In this region, the oxygen concentration in equilibrium changes

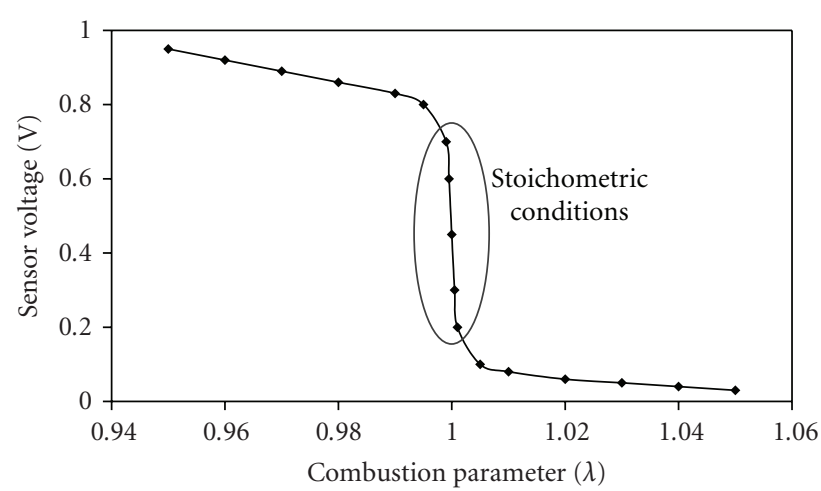

FIGURE 5: Typical response of a potentiometric oxygen sensor in terms of the combustion parameter $\lambda$.

in several orders of magnitude. Therefore, in practice, this kind of sensors works with a binary response, rich/lean. The determination of the rich/lean conditions is a useful information in combustion control.

Regarding other characteristics of the electric response, these sensors may offer excellent response times (no more than hundreds of milliseconds) in both oxidizing and reducing atmospheres. The response is dependent on temperature, not only due to thermal activation of ionic conduction and the $T$ dependence in (2) but also because of the temperature influence on catalytic conversion in the electrodes. This causes a local $p_{\mathrm{O}_{2}}^{*}$ dependence on the temperature near the metal electrodes.

Ceramics offer strong mechanical stability and thermal stress resistance. This helps to keep the behavior of the sensor not so dependent on ageing effects. However, structural phase transitions in some regions of the ionic conductor and a low degradation of the electrodes may appear through a long time of usage (above hundreds of hours of operation). This can affect the response, specially the response time.

2.3. Sensors without Air Reference. In the recent years, some planar oxygen sensors have been designed without air reference. Its structure consists in

\section{Measured gas/Electrode1/Ion conductor/}

Electrode 2/Measured gas.

As said before, the physical principles governing the behavior of ion-conducting oxygen sensors are the same for both thimble and planar-type sensors, even in the case of no air reference in one of the electrodes. Equation (2) would be perfectly applicable to a sensing element with no air reference, that is, with both electrodes exposed to the same gas. However, as the two electrodes would detect the same oxygen partial pressure $p^{*}$, a zero voltage would be obtained:

$$
V_{\mathrm{OC}}=\frac{k_{B} T}{4 e} \ln \frac{p^{*}}{p^{*}}=\frac{k_{B} T}{4 e} \times 0=0 \text { volts. }
$$

In order to provide nonzero potentiometric responses, commercial and experimental sensors with no air reference 
usually incorporate a metal catalyst different from $\mathrm{Pt}$ or a metal oxide in one of the electrodes. This introduces different working functions in each electrode and provides an additional output voltage [6-10].

Using different materials in each electrode in sensors with or without air reference is a way to improve selectivity to oxygen or to other molecular species. Nanomaterials are currently a useful tool to improve selectivity, as will be shown in Section 4.2.

\section{Steady-State Response of the Potentiometric Sensor}

From a qualitative point of view, oxygen molecules in both measuring and reference electrodes are in local equilibrium with the nearest oxygen ions in the electrolyte, due the reaction

$$
\begin{aligned}
& \mathrm{O}_{2}+4 \mathrm{e}^{-} \rightleftarrows \quad 2 \mathrm{O}^{2-} \\
& \text { (gas) } \quad \text { (electrode) }
\end{aligned}
$$

When the oxygen concentration in the measuring atmosphere is not the same as in the reference atmosphere, the electrochemical cell of the sensor is pushed to a nonequilibrium state, as two different $\mathrm{O}^{2-}$ local concentrations near the two respective electrodes are demanded to reach equilibrium (6) with oxygen molecules in contact to each electrode. The distribution of oxygen ions across the electrolyte is altered to reach equilibrium. As a consequence, a nonzero voltage must be detected between the electrodes due to this nonuniform charge distribution across the ion-conductor.

3.1. Derivation of the Nernst Voltage. The ideal Nernst open circuit voltage can be easily derived from elementary thermodynamics. The Gibbs free energy of a molecule, $G$, is

$$
G=H-T S=H-k_{B} T \ln \Omega,
$$

where $H$ is the enthalpy, $S$ is the entropy, and $\Omega$ is the number of states available to the molecule. This number of states must vary linearly with the volume of the system, which is inversely proportional to the oxygen partial pressure, $p^{*}$. Therefore, $G$ can be rewritten as

$$
G=H-k_{B} T \ln \left(\text { constant } \times p^{*}\right) .
$$

If the oxygen partial pressure in the measured and reference gases is different, their respective Gibbs free energies, $G_{M}$ and $G_{R}$, will be also different. Thus, this difference in Gibbs energies between oxygen molecules in the two atmospheres must be

$$
\begin{aligned}
\Delta G & =G_{M}-G_{R} \\
& =\Delta H-k_{B} T\left[\ln \left(\text { constant } \times p_{M}^{*}\right)-\ln \left(\text { constant } \times p_{R}^{*}\right)\right] \\
& =\Delta H+k_{B} T \ln \frac{p_{R}^{*}}{p_{M}^{*}},
\end{aligned}
$$

where $p_{R}^{*}$ and $p_{M}^{*}$ are the oxygen partial pressures in the reference and measured gases, respectively.

This energy difference must be equal the difference of electric energy $\Delta U$. As four electrons are transferred in reaction (6), $\Delta U=-4 e \Delta V$. Thus,

$$
\Delta V=V_{R}-V_{M}=\frac{k_{B} T}{4 e} \ln \frac{p_{R}^{*}}{p_{M}^{*}},
$$

where $V_{R}$ and $V_{M}$ are the electric potentials of the reference and measuring electrode, respectively.

The use of Gibbs energy in this derivation and other descriptions concerning the sensors behavior has been widely replaced by the use of the electrochemical potential $[11,12]$, $\tilde{\mu}=\mu+q \cdot V$, where $\mu$ is the chemical potential and $V$ is the electric potential. Note that $\tilde{\mu}$ and $\mu$ have energy dimensions although they are called potentials by abuse of language.

3.2. Classical Models of the Potentiometric Response. As seen in the previous section, to derive the Nernst voltage it is assumed that there is only ionic conduction in the electrolyte and both electrodes are catalytically active. The resulting Nernst equation (2) shows no dependence on the electrodes and electrolyte characteristics; that is, the theoretical equilibrium voltage is the same whatever the physicochemical properties of the sensor are.

However, experiments have shown that the output voltage is dependent on the properties of the electrodes and the electrolyte, not only in the transient process but also in steady-state conditions. Nonideal behavior is easily observed under reducing atmospheres. Response differences between sensors led some authors to model their respective behavior in terms of their different properties. Also, Nernst equation is derived assuming that thermodynamical equilibrium is reached; that is, no faradic current across the sensor is detected. As a consequence, processes of adsorption, reduction, or desorption of different molecular species in the electrodes are not contemplated in Nernst equation as the sensor would provide then a rate-determined response instead of an equilibrium response.

The first models of the behavior of potentiometric oxygen sensors were developed for automotive applications and focused on the sensors response when exposed to engine air/fuel mixtures. These models took into account the interaction between different molecular species in the electrodes. They are considered to model the behavior of non-Nernstian sensors or mixed potential sensors.

Comparisons between ideal and experimental sensor voltage curves led Fleming [3] to the following considerations.

(i) $\mathrm{CO}$ is the main reducing gas which may adsorb onto Pt electrodes [13]. Therefore, CO is assumed to be the unique gas apart from $\mathrm{O}_{2}$ to affect sensor voltage.

(ii) $\mathrm{CO}$ may deplete the local oxygen partial pressure near the measuring electrode via the reaction:

$$
2 \mathrm{CO}+\mathrm{O}_{2} \rightleftarrows 2 \mathrm{CO}_{2} \text {. }
$$

The resulting oxygen concentration in equilibrium after reaction (11) is responsible of the ideal equilibrium Nernst voltage in reducing mixtures. 
(iii) However, CO may affect the sensor voltage by depleting directly the oxygen ions in the electrolyte near the measuring electrode:

$$
\underset{\text { (gas) }}{\mathrm{CO}}+\underset{\text { (electrolyte) }}{\mathrm{O}^{2-}} \underset{\text { (gas) }}{\rightleftarrows} \quad \mathrm{CO}_{2}+\underset{\text { (electrode) }}{2 \mathrm{e}^{-}}
$$

(iv) The open circuit voltage results from the superposition of two Nernst voltages linked with the two previous reactions:

$$
V_{\text {out }}=\alpha \times V_{\text {reaction } \mathrm{O}_{2}}+\beta \times V_{\text {reaction CO. }}
$$

(v) The equilibrium voltages $V_{\text {reaction } \mathrm{O}_{2}}$ and $V_{\text {reaction CO }}$ can be calculated in terms of estimated equilibrium constants for reactions (6) and (12), respectively.

(vi) The parameters $\alpha$ and $\beta$ depend on the fraction of adsorption sites occupied by $\mathrm{O}_{2}$ and $\mathrm{CO}$ species in the platinum electrodes. They can be estimated in terms of heat adsorption for $\mathrm{CO}$ and $\mathrm{O}_{2}$ on $\mathrm{Pt}$ and thermodynamical constants.

Thus, the output voltage in front of the engine air/fuel ratio is considered as a function of four parameters: the equilibrium constants for two chemical reactions and the fraction of $\mathrm{CO}$ and $\mathrm{O}_{2}$ adsorbed molecules in platinum. Additionally, this model contemplated the possibility of different electron electrochemical potentials between the two electrodes. The steady-state high voltage in nonequilibrated reducing mixtures is explained with this ancient model even in actual planar Pt/YSZ/Pt potentiometric sensors. Fleming also provided a first model to understand why the step voltage from high to low values was not always so abrupt and did not appear at a same gas composition in all sensors [3].

Fleming's model was later improved by Anderson and Graves [14] to study the characteristics of the commented voltage step for a certain gas composition. They took into account the adsorption fraction for $\mathrm{O}_{2}, \mathrm{CO}$, and also $\mathrm{CO}_{2}$ and considered the existence of a gaseous boundary layer between the bulk gas region and the electrode/catalyst surface. They used the same equations as in Fleming's model for the steady-state adsorpted species but additionally assumed a transient mass transfer of $\mathrm{O}_{2}, \mathrm{CO}$, and $\mathrm{CO}_{2}$ between the bulk gas and the boundary layer and certain transient adsorption/desorption rates in the electrode. By solving numerically the system, steady-state oxygen concentrations in the electrode were found.

Anderson focused on calculations for estimating the sensor voltage when exposed to different $\mathrm{O}_{2} / \mathrm{CO}$ mixtures. $\mathrm{He}$ took into account the effect of different surface reaction rate constants in the electrodes and found different theoretical voltage curves in terms of the reaction rate constant of the reaction

$$
\mathrm{O}_{2}+2 \mathrm{CO} \longrightarrow 2 \mathrm{CO}_{2}
$$

and its inverse reaction rate constant. In the case of lower reaction constants for oxygen combustion, that is, a higher inverse reaction rate than the reaction rate of (14), voltage curves did not show the step-like behavior shown in Figure 5 .
Also, the calculated responses in sensors with identical reaction rate constants but different mass transfer rate constants were compared. It was shown that differences in the dynamic process (changes in mass transfer across the hypothetic boundary gas or in the reaction rate constants) may cause differences in the steady-state response and not only in the transient response. This is not reflected in Nernst equation as it only takes into account the equilibrium oxygen partial pressure in front of the electrodes, without considering the process which leads to this local oxygen partial pressure.

Up to now, the commented models did not take into account the possibility of implementing a protective, diffusive layer schematically similar to the one shown in Figure 1, although this last work contemplated a hypothetical diffusive gas boundary layer. Saji et al. [15] used YSZ sensors with a porous ceramic coating over the measuring electrode. A same sensor was exposed to different oxygen/combustion gas mixtures at different temperatures, and different voltage steps were found again depending on the combustion gas. In experiments with different gas mixtures, the voltage step appeared at a different combustion parameter. In fact, differences in the step voltage characteristics were observed in mixtures as similar as nonequilibrated $\mathrm{H}_{2}-\mathrm{O}_{2}-\mathrm{N}_{2}$ and $\mathrm{D}_{2}$ $\mathrm{O}_{2}-\mathrm{N}_{2}$. A different combustion voltage step for hydrogen and for deuterium suggested an influence of the molecular mass in the response.

These results and the observed differences in temperature led Saji to develop a more complete model of the sensors steady-state response. According to this model, the sensors response depends on three temperature-activated phenomena:

(i) spontaneous equilibration of the initially nonequilibrated gas mixture,

(ii) oxygen reactions in an electrode-electrolyte contact following (6),

(iii) carbon monoxide reactions following (12).

At a high enough temperature (over $900 \mathrm{~K}$ ), step voltages were observed at the stoichiometric oxygen/combustion gas mixtures. This measurements, along with evidences suggesting that gas phase reactions occur spontaneously in gas mixtures containing oxygen and combustible gas at high temperatures, with no need of a Pt catalyst, made Saji assume that the gas mixture was equilibrated in the measuring electrode and the voltage was in accordance with the predicted ideal Nernst voltage. In a middle temperature region $(650-800 \mathrm{~K})$, there was still no spontaneous reaction and the gas mixture entered the porous coating without chemical equilibration. As mass transport across a porous layer is governed by diffusion and each molecule has a different diffusion coefficient, steady-state concentrations across the ceramic coating were different for the different gas species (Figure 6). Assuming that the pore diameter is much less than the mean free path of the gas molecules (Knudsen diffusion), Saji found the following equation to calculate the 


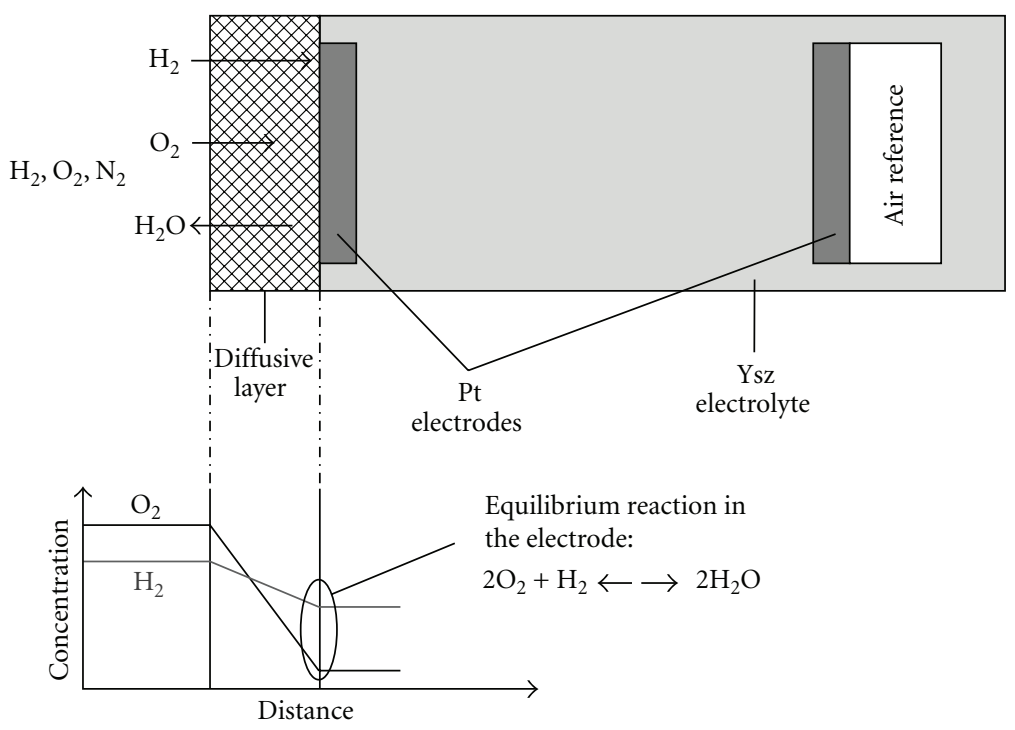

Figure 6: Representation of the diffusion of $\mathrm{O}_{2}$ and $\mathrm{H}_{2}$ across a porous layer covering one of the electrodes. According to Saji et al. [15], diffusion of the molecular species may lead to important differences between the bulk gas concentration and the measured concentration in the electrodes. This would justify differences in the step voltage in some gas mixtures.

gas mixture composition where the step voltage appeared:

$$
\begin{aligned}
& \frac{\left.\frac{\text { oxygen concentration }}{\text { combustion gas concentration }} \text { (voltage step }\right)}{\left.\frac{\text { oxygen concentration }}{\text { combustion gas concentration }} \text { (stoichiometric }\right)} \\
& =\sqrt{\frac{M_{\mathrm{O}_{2}}}{M_{\text {combustible gas }}}}
\end{aligned}
$$

where $M_{x}$ is the molecular mass of the component $x$. This model was in agreement with experimental data and explained why the voltage step for deuterium was different from the one for molecular hydrogen. Last, in a lowtemperature region (below $650 \mathrm{~K}$ but at a temperature high enough to provide ionic conduction), reactions (6) and (12) and Fleming's original considerations were applicable.

Several experimental measurements with potentiometric sensors [16-20] led Brailsford et al. to try to develop similar models for both transient and equilibrium sensor responses when exposed to mixtures containing $\mathrm{O}_{2}, \mathrm{CO}, \mathrm{CO}_{2}, \mathrm{H}_{2}$, and $\mathrm{H}_{2} \mathrm{O}[21,22]$. Apart from considering different adsorption rates and the same possible reactions in the measuring electrode as in previous models, an additional reaction of adsorbed $\mathrm{CO}$ with adsorbed $\mathrm{H}_{2} \mathrm{O}$ (a "water-gas" reaction) in the electrode was modeled. By comparing the Brailsford model to an hypothetic water-CO reaction [20], the voltage curve was not well fitted, at least at medium temperatures $(631 \mathrm{~K})$. At high temperatures $(837 \mathrm{~K})$, no big differences were observed between models with and without this reaction. Works of Brailsford et al. were useful for understanding the effects of various physicochemical processes involved in the operation of electrochemical sensors. However, their modeled $\mathrm{CO}-\mathrm{H}_{2} \mathrm{O}$ interaction appeared to be not necessary.
Fleming's model [3] and the later modifications incorporated competing reactions at the adsorption sites (i.e., the three-phase boundary sites) in the electrodes, for instance, one for oxygen (6) and another one for carbon monoxide (12). What Fleming characterized with adsorption and desorption constants for different gas species was later extensively considered as mixed potential of the potentiometric sensors.

3.3. Three-Phase Boundary. Up to now, a few electrodes characteristics have been considered: the main classical models of the sensor response focused on the interacting gases and the rates of reaction, adsorption, and desorption for each molecule species in the electrodes. As seen, this provided useful information to understand the sensors performance and good agreements between experimental and calculated data was generally obtained. However, the sensor was considered as a black box, with almost no influence on the response in terms of the electrode morphology or the electrolyte characteristics.

Morphological and catalytic properties of the electrodes are important to obtain an appropriate response. Moreover, models of the behavior of electrodes are important for current trends on implementation of nanomaterials as catalysts in this kind of sensors and in solid oxide fuel cells as well.

The triple phase boundary (TPB) is an important concept for studying processes in the electrodes. TPB sites are the regions where the measured atmosphere, the metal catalyst, and the electrolyte coexist. Reactions in electrochemical systems involving ion-conduction can only appear in TPB sites or nearly zones if the sensing electrode is metallic. For instance, reaction (6) is assumed to occur only where $\mathrm{O}_{2}$ molecules can reach a Pt/YSZ contact zone. Otherwise it is 


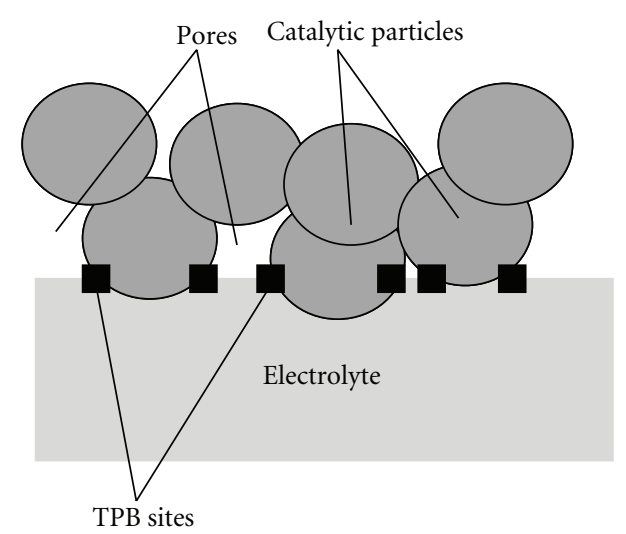

Figure 7: Scheme of the three-phase boundary sites in an interface electrode-electrolyte. Porous electrodes help increasing the density of three-phase boundary sites.

not possible to exchange electrons from the metal and change the amount of oxygen ions in the electrolyte.

Several works have confirmed the dependency of the electrode performance on the length of three-phase boundary sites [23-25], and different electrode configurations lead to different TPB lengths. We can define, regarding their TPB density, three types of suitable electrodes for potentiometric oxygen sensors: nonporous metallic electrodes, porous metallic electrodes, and cermet electrodes. Works on the three-phase boundary sites have been mainly focused on solid oxide fuel cells, but their results are perfectly applicable to electrochemical sensors.

Reactions in a nonporous pure metallic electrode are relatively difficult as the TPB sites are located exclusively in the contour of the electrode in contact with the electrolyte. Although gas molecules may adsorb in the entire surface of the electrode, most of them cannot react providing or extracting oxygen ions from the electrolyte as the contacts gas/catalyst/electrolyte are only in the contour of the electrode. This low density of TPB sites causes a current constriction as a high fraction of the contact area between metal and YSZ is inactive [26, 27]. Subsequently, the response time of sensors with this structure is slow. Hertz and Tuller [28] developed a model on the current constriction in TPB. Also, the response of the sensors may worsen due to ageing, as slight contaminations of the electrodes may affect a large fraction of three-phase boundary sites, given that most of them are allocated in a same region.

An improved configuration for electrodes in oxygen sensors is a porous metal electrode. Most of the commercial oxygen sensors incorporate porous Pt electrodes, as gas molecules can diffuse across the pores and the density of TPB sites increases $[25,29,30]$. Figure 7 shows a scheme of the structure of the interface porous Pt electrode/YSZ electrolyte. SEM images of the surface of porous Pt electrodes can be seen, for instance, in [29].

An electrode made of a ceramic/metal composite is known as a cermet electrode. These electrodes provide even more TPB sites. Using a porous $\mathrm{Pt} / \mathrm{YSZ}$ composite instead of a metal phase over the YSZ electrolyte multiplies the number of interfaces between the catalyst and the electrolyte [31]. TPB length is increased and problems with current constriction are avoided. Some authors have worked on the dynamics of TPB sites in these composites, as thermal and electrochemical history of the system may affect the TPB length [32-35]: for instance, high polarizations may modify the morphology of the electrode or block some fractions of the interfaces between Pt/YSZ with oxygen molecules or ions.

As an alternative to $\mathrm{Pt} / \mathrm{YSZ}$ cermet electrodes, other cermet electrodes consisting in metal oxides mixed with a metal catalyst have been proposed in order to modify the mixed potential of the sensors and/or improve gas selectivity due to the promotion of one of the competing chemical reactions in the catalysts. For instance, selectivity to $\mathrm{O}_{2}$ has been reported with $\mathrm{NiO}$ [36], $\mathrm{CdO}$ and $\mathrm{SnO}_{2}$ for $\mathrm{CO}$ selectivity [37], $\mathrm{ZnO}$ for $\mathrm{H}_{2}$ selectivity [38], $\mathrm{CdMn}_{2} \mathrm{O}_{4}$, $\mathrm{CdCr}_{2} \mathrm{O}_{4}$, and $\mathrm{WO}_{3}$, among others, for $\mathrm{NO}_{x}$ selectivity [3942]. Nanomaterials have been applied to modify the mixed potentials and enhance gas selectivity, as it will be shown in the next section.

An interesting model of the transient and steady-state response of the potentiometric sensor including the classical views of the first models, mixed potentials, reaction rates, possible diffusion of molecular species, and TPB dynamics was developed by Zhuiykov [43, 44].

Zhuiykov considered a planar non-Nernstian potentiometric YSZ sensor with dissimilar electrodes: one made of porous platinum and the other one made of porous $\mathrm{NiO}$ deposited on a porous $\mathrm{Pt}$ film. The fact that Pt was porous improved the TPB sites density. No air reference was designed; that is, the two electrodes were exposed to the same atmosphere. The model studied the response to a $\mathrm{NO}_{2} / \mathrm{O}_{2} / \mathrm{H}_{2} \mathrm{O}$ mixture. The following phenomena were considered:

(i) multicomponent diffusion of gaseous species through the porous electrodes; ordinary bulk diffusion as well as Knudsen and surface diffusion was modelated,

(ii) adsorption, desorption, and partial dissociation of nitrogen dioxide within the solid oxide electrode,

(iii) dissociation of water in the three-phase boundary sites,

(iv) cathodic reaction of $\mathrm{NO}_{2}$ in the three-phase boundary and in the electrode bulk of the solid oxide electrode,

(v) electrochemical reaction of oxygen, following equation (6).

All the electrochemical reactions were assumed to occur at different kinetic rates in each electrode as their composition was different. This model offered a more detailed description of the main phenomena in this kind of potentiometric sensors. Also, some electrochemical stages were assumed to occur only in the TPB sites whereas some other phenomena were considered in the bulk electrodes and in the TPB sites as well. The competition of different rates for each electrochemical stage, together with time-dependent equations 
for multicomponent gas diffusion phenomena, led Zhuiykov to get a transient and steady-state response of the sensor which was experimentally verified. Some phenomenological parameters which had been introduced in previous models $[45,46]$ were eliminated with this more detailed description. Moreover, this model could be extended to other nonNernstian planar gas sensors with dissimilar electrodes.

Muroto et al. studied the dynamic behavior of the electrodes, with special emphasis on phenomena of activation and degradation of Pt/YSZ three-phase boundary sites and, generally, Pt/YSZ interfaces [47]. They proposed a scheme of the interface electrode-electrolyte and a representation of all the possible electrochemical driven changes (i.e., polarizing the sensor) and temperature effects. In particular, they found that low polarizations between the two sensor electrodes under certain controlled atmospheres might partially scratch some regions of the electrode, promoting electromigration of platinum and leading to the possible creation of new three-phase boundary sites. Thus, imposing an external polarization to the sensing devices could increase the density of TPB sites and subsequently improve the catalysis as well as lower the electrode impedance and response times. However, a too high polarization could damage the electrode due to cracking the platinum or promoting the formation of air bubbles between platinum and YSZ, lowering the effective density of TPB sites.

Ramamoorthy et al. [48] compared the response time of sensors with different metallic and metal oxide electrodes and tried to correlate to the charge transfer processes in the three-phase boundary sites. Although the total time of response was not only determined by the characteristic time of processes in electrodes, it was found that the fact that charge transfer reactions occur only in TPB sites in Pt electrodes leads to a current constriction phenomenon which is not observed in some complex metal oxide electrodes such as lanthanum strontium iron cobalt oxide (LSFCO). They made use of impedance spectroscopy in this work. Applications of this technique will be commented in next section.

3.4. Equivalent Electric Models and the Use of Impedance Spectroscopy. Characteristics and behavior of electrochemical sensors in terms of their equivalent electric models. In this field, impedance spectroscopy is a powerful tool to characterize electrically the oxygen sensors and fit their modeled electrical components.

Impedance spectroscopy is performed by means of a potentiostat who applies an external AC voltage to the sensor electrodes and detects a current in a wide range of frequencies. The corresponding impedance is calculated for each frequency. Imaginary versus real impedance is represented in terms of frequency. An alternative way to represent impedance spectra is using Bode diagrams.

In a first approximation, a typical electrochemical gas sensor can be electrically modeled as shown in Figure 8. As electrodes can exchange electrical charge following equation (6) and charges can be stored in the electrode structure or in the interface electrode-electrolyte [49], the two electrodes of the sensor are assumed to behave like a resistor in parallel to a capacitor. Ceramic electrolytes are usually

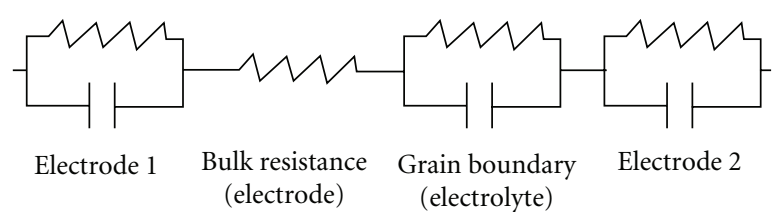

Figure 8: Minimum equivalent electric circuit of an oxygen sensor to fit to impedance spectra.

considered as a resistor in series with a parallel resistorcapacitor. As indicated in Figure 8, this represents the bulk (or intragranular) contributions and grain boundary (or intergranular) contributions.

More complex electrical models can be tried depending on the desired level of fitting accuracy or the needs of separating contributions from bulk, grain boundary, second phase, surface layer contributions, and so forth. For instance, a very low capacitor can be modeled in parallel to the resistance of the intragranular contributions, as bulk crystals are not perfect [50]. Also, capacitances in the electrodes and in the electrolyte can be replaced by constant phase elements. [48, 51-53]. Inductance contributions [54] or Warburg diffusion phenomena in electrodes [50, 55-57] can be implemented as well. Considerations on how to carry out impedance spectroscopies in ceramic materials and how to model and treat the measured data can be found at [58-61].

Meng and Shen [62] showed an example of an electrical model of an unconventional sensor with Pt-free electrodes: $\mathrm{Ag} / \mathrm{C}$ and $\mathrm{Ag}-\mathrm{W}_{2} / \mathrm{C}$ electrodes. The electrolyte was modeled just with a single resistance as no capacitive effects were seen in the electrolyte in the range of the applied frequencies. Constant phase elements were introduced in the arcs corresponding to electrode contributions. Generally, it may be necessary to introduce constant phase elements in the electrodes instead of capacitors as they fit better impedance data when double layer capacitance effects (i.e., current constriction in the interface electrode-electrolyte) are present. With this model, the impedance spectra of the Ag- $\mathrm{W}_{2} / \mathrm{C}$ would not be correctly fitted: it was necessary, in this case, to introduce a Warburg diffusion impedance due to mass transport phenomena in the electrode. Impedance data helped, in this case, to proof a faster kinetic process of oxygen reduction on the $\mathrm{Ag}-\mathrm{W}_{2} \mathrm{C} / \mathrm{C}$ catalyst. Warburg diffusion is a representation of mass transport in the electrode instead of charge transport.

The influence of the electrode characteristics in the sensing response can be tested by impedance spectroscopy. As introduced before, Ramamoorthy et al. [48] compared three different electrodes for YSZ potentiometric oxygen sensors: platinum, lanthanum strontium iron cobalt oxide (LSFCO), and chromium oxide and correlated with the sensors response. It was found that the characteristic time of electrochemical reactions was controlled by resistance in Pt and chromia electrodes and by capacitance in LSFCO electrodes, but this was not the phenomenon who limited the response time of the sensor. These data suggested that the high response time in the sensors was due to surface diffusion of oxygen adsorbates, which was influenced by the electrode microstructure. 
Regarding the sensor response, Frade et al. [63] observed that variations in the sensor response after polarizing the electrodes might be correlated by impedance spectroscopy. They also established relations between consequences of polarizing the sensor and the thickness and transport properties of the solid electrolyte.

Separating the different contributions in the electrolyte and the electrode is a key point when extracting information from impedance spectroscopy. First, the impedance of the two electrodes may be overwritten in the impedance spectra. Thus, it is relatively usual to design some test sensors with three electrodes in order to use an additional reference electrode. This helps separating the RC contributions for each electrode $[64,65]$. Due to their differences in resistance and capacitance, it is relatively easy to separate electrode arcs from electrolyte arcs $[26,27,58,66]$, but problems arise for detecting bulk and grain boundary contributions in the electrolyte $[67,68]$. Separating intragranular and intergranular contributions in the ceramic electrolyte may be useful to observe differences in the sintering process [69], to compare conductivities in YSZ with different yttria contents [70] or to analyze the effect on adding some $\mathrm{MgO}$ content to YSZ [68].

Some works have tried to establish general patterns for describing the factors determining the electrolyte conductivity [71]. However, high dispersion in conductivity measurements have been found in different works as a high number of parameters may affect the resistance of the electrolyte, not only the measurement conditions but also fabrication parameters, thermal history of the electrolyte, grain size, and so forth. A large discussion on the role of the grain boundaries in the total conductivity of ion-conducting ceramics was done by Guo and Waser [72]. They focused on models of space charge layers for describing grain-to-grain contacts.

\section{Improving Potentiometric Oxygen Sensors: Current Trends on the Use of Nanomaterials}

Research in nanomaterials has been carried out extensively in the recent years. The use of nanostructures shows usually similar advantages in different disciplines: miniaturization, material savings, lower energy consumption, and new physical and chemical properties due to scale effects.

Nanotechnology is an interesting research ambit in the field of electrochemical gas sensors. The use of nanomaterials has provided some improvements on the classical oxygen sensors, whose models of behavior have been presented in the previous sections. However, works on nanomaterials for oxygen sensing devices have been essentially for academic purposes and not yet commercially applied, as much research has to be done in the future. Moreover, research focuses on the development of solid oxide fuel cells, although these devices share most of their physicochemical properties with electrochemical sensors.

Göpel [73-75] commented on the possibility of hypothetic electrochemical nanosensors with the structure $\mathrm{Pt} / \mathrm{YSZ} / \mathrm{Pt}$ but appreciated several difficulties in its miniaturization. For instance, relatively large Pt clusters are required to form a spatially coherent net of an electron conducting contact which allows the oxygen molecules to access the three-phase boundary, as large differences in the surface free energies between platinum and YSZ cause adhesion problems. Göpel suggested also that it would be hard to prepare epitaxial thin films with a structural control in the monolayer range.

More recently, Huang and Choi [76] commented some other problems and future challenges regarding the use of nanomaterials for gas sensing. For instance, mechanisms, such as pore diffusion or reactions of molecular oxygen, adsorbed oxygen or oxygen ions, and parameters like surfaceto-volume ratios, have been intensely investigated in gas sensors, but further research is required to take account of these mechanisms coupled with particular nanostructures in the sensors. Selectivity could be improved with a more precise knowledge in this area.

Works with nanomaterials have focused on the improvements of the sensor characteristics. In the context of potentriometric ion-conducting oxygen sensors, we can divide the use of nanomaterials in these devices in three separate groups:

(i) nanomaterials for lowering the electrode impedance, for instance, increasing the density of TPB sites, avoiding current constriction in the electrode/electrolyte contacts, or lowering the surface free energy between the electrode and the electrolyte,

(ii) nanomaterials for improving gas selectivity for oxygen or other gas species by enhancing catalysis in the electrodes or by modifying the mixed potential of the electrodes, here, semiconducting oxides have been tried as an alternative to pure metal catalyst electrodes,

(iii) nanomaterials for designing thin film electrolytes in order to lower the activation energy for ion-conduction and enabling lower operation temperatures.

4.1. Lowering the Electrode Impedance. As seen before, one of the most important elements in electrochemical oxygen sensors is the three-phase boundary. A high number of TPB sites ensures a good response time as it lowers the double layer capacitance. As the use of porous Pt, Pt-YSZ composites or other cermet composites is a good way to improve the TPB density, it seems obvious that particles with lower grain size and higher specific surface help enlarging the number of TPB sites.

Kimura and Goto [77] looked for an alternative to Pt in the electrodes and found that iridium may have similar or higher catalytic activity than Pt. They prepared Ir-YSZ nanocomposite electrodes by metalorganic chemical vapor deposition (MOCVD). The composite consisted in crystalline Ir and amorphous YSZ, with an average Ir particle size of $3 \mathrm{~nm}$. Several composites were prepared with a controlled Ir composition from 3\% to $71 \%$ vol. It could be seen that the electrical conductivity was up to 1000 times higher than that of Pt electrodes.

Later, the electrochemical performance of $\mathrm{IrO}_{2} / \mathrm{YSZ}$ nanocomposite electrodes was investigated by Torres-Huerta et al. [78], with grain sizes between 15 and $30 \mathrm{~nm}$. Although 
this work was in the area of fuel cells, the observed properties are applicable to gas sensors. The modeled equivalent circuits after impedance spectra suggested that the polarization resistance was lower than in Pt conventional electrodes and Ir-YSZ electrodes [77], probably due to a higher density of triple phase boundary sites. Furthermore, the activation energy for the interfacial conductivity of the composites was in agreement with the energy of dissociation of oxygen molecules. By comparing to the activation energy for LSM or Pt electrodes [79], the authors suggested that the $\mathrm{IrO}_{2}$ YSZ cermets might offer an efficient and competitive performance as electrode materials for YSZ electrolytes, although further analysis would be necessary.

An interesting improvement of the electrodes impedance was proposed by Wang et al. [80], also valid for fuel cells and electrochemical gas sensors. Based on quantum $\mathrm{ab}$ initio calculations, it was found that both the surface energy of a $\mathrm{Pt}_{0.7} \mathrm{Ni}_{0.3}$ cluster and the energy change of the Pt-Ni alloy cluster upon ripening on YSZ were lower than pure $\mathrm{Pt}$. Also, changes in microstructure properties after annealing nanoporous $\mathrm{Pt}$ and $\mathrm{Pt}-\mathrm{Ni}$ thin films were compared. No changes were found in Pt-Ni nanoporous thin films, but a dramatic porosity reduction was observed in pure nanoporous platinum. Therefore, a lower electrode impedance, better thermal stability, and lower temperature of operation were expected.

The use of nanocomposites made of $\mathrm{Pt}$ mixed with carbon nanotubes has sometimes been suggested [81] to be applied in oxygen sensors. However, they have been implemented just in some hydrocarbon electrochemical sensors [82] or biosensors [83] have been designed with those nanocomposites.

\subsection{Promoting Catalysis and Enhancing Gas Selectivity.} Nanostructured materials are a useful tool to improve sensitivity and selectivity in potentiometric ion-conducting sensors as well as in sensors with other sensing principles. The use of nanoparticles as catalyst, for instance, may owe larger surface areas and, subsequently, higher catalytic activities than in bulk material catalysts. This should help maximizing the response. However, as said before, it is necessary to know the interactions between the gas being monitored and the nanostructures to get reliable and repetitive results.

In order to improve catalysis as well as electrode impedance in the electrocatalytic reduction of dissolved oxygen, Britto et al. [84] made use of carbon nanotube microelectrodes. Although their interest was improving the behavior of solid oxide fuel cells, results regarding the exchange current densities in the electrode are interesting when compared to graphite paste electrodes. It was found that an electrode made of carbon nanotubes showed an exchange current density of about 6 times the current density in electrodes made of graphite. However, an electrode made of carbon nanotubes with deposited palladium had an exchange current density of $10^{5}$ times the graphite paste electrode. This important change in the charge transfer together with the fact that reactions between oxygen and hydrogen are usual in some measurements with oxygen sensors could help promoting oxygen selectivity as well as lowering the electrode impedance.

Later, Collins et al. [85] showed that carbon nanotubes are highly sensitive to the chemical environment in the case of single wall carbon nanotubes, electrical resistance, local density of states by direct exposition to air, different concentrations of dissolved oxygen, or very small amounts of adsorbed gases. The results of this work, therefore, showed that although selectivity and sensitivity to oxygen was excellent and this could have been a tool to improve the performances of oxygen sensors in the electrodes, the use of carbon nanotubes does not seem to be an easy tool to future developments in oxygen sensing with catalytic electrodes, as many properties are extremely dependent of the design process or some extrinsic conditions.

More recently, Cvelbar and Mozetič [86] studied an unconventional improvement on the catalysis by using a $\mathrm{Nb} 2 \mathrm{O} 5$ nanowire array at the outer surface of an originally developed catalytic oxygen sensor. Thanks to the higher surface areas, a stronger catalysis than in a conventional catalyst was obtained. Also, oxygen atoms generated from dissociation of molecular oxygen were detected at densities of up to ten times lower than in conventional bulk catalysts. The results suggested that nanowire-based sensors could be used to detect small densities of gases (oxygen or other species) in environments where standard catalytic probes fail.

Not many works have focused on improvements in catalysis by means of nanomaterials in the electrodes for potentiometric oxygen sensors based on an ion-conducting electrolyte. However, electrodes of ion-conducting oxygen sensitive devices have been modified with nanostructured materials to promote selectivity to some gases in multicomponent gas mixtures with presence of oxygen. As will be shown, metal oxide nanoparticles have been useful to modify the mixed potential in the electrodes in non-Nersntian planar sensors.

As said before, the competition of reactions such as (6) for oxygen or (12) for carbon monoxide in metal catalysts had been already introduced in the classical models of the sensors response and suggested the concept of mixed potential. Modifying the mixed potential in an electrode can lead to a different sensor output voltage when exposed to certain gas mixtures. In fact, the combination of different electrochemical cells covered by different electrode materials can promote a net selective response to concrete molecular species. Some commercial sensors in automotive applications are based on this possibility.

Devices with some of these new electrodes suggest future development on new commercial selective gas sensors. For instance, $\mathrm{Wu}$ et al. [87] proposed the use of a porous $\mathrm{CuO}-\mathrm{ZnO}$ nanocomposite over a Pt conventional paste. The structure $\mathrm{CuO}-\mathrm{ZnO} / \mathrm{Pt} / \mathrm{YSZ} / \mathrm{Pt}$ was studied as a selective $\mathrm{CO}$ sensing electrode. A high porosity was observed in the structure of the $\mathrm{CuO}-\mathrm{ZnO}$ nanocomposite electrode. An output voltage of about $8 \mathrm{mV}$ was detected for a $800 \mathrm{ppm}$ $\mathrm{CO}$ concentration in air near $800 \mathrm{~K}$. However the response equilibration time of the sensor was significantly slow, in the order of thirty minutes. 
Li and Kale [88-91] studied electrodes made of tindoped indium oxide (ITO) nanoparticles. Sensors with the structure ITO nanoparticles/YSZ/Pt exposed to air mixed with several CO concentrations near $900 \mathrm{~K}$ got higher sensitivities for $\mathrm{CO}$ and lower potentiometric response times than in previous works. This net response is non-Nernstian and was attributed to the mixed potential of electrodes made of ITO nanoparticles.

In an opposite direction, Plashnitsa et al. [92] studied a mixed potential sensor with almost no selectivity to carbon monoxide and other species such as hydrocarbons. By using gold nanoparticles coatings as sensing electrodes, sensitivity of $400 \mathrm{ppm} \mathrm{CO}$ in air was lowered to less than $10 \mathrm{mV}$ at $870 \mathrm{~K}$, whereas sensitivity to $400 \mathrm{ppm} \mathrm{NO}_{2}$ was promoted to $60 \mathrm{mV}$. The obtained high sensitivity and high selectivity to $\mathrm{NO}_{2}$ were attributed to the higher catalytic activity of the reaction

$$
\mathrm{NO}+\mathrm{O}^{2-} \rightleftarrows \mathrm{NO}_{2}+2 e^{-}
$$

in the $\mathrm{Au} / \mathrm{YSZ}$ interface than the catalytic activity of reaction (12), causing a modification of the respective mixed potentials. This work showed big differences between the behavior of electrodes with gold nanoparticles and gold bulk electrodes, as bulk Au electrodes had been described for mixed potential sensors for detection of $\mathrm{CO}$ [93-95] and hydrocarbons [92, 96, 97].

More nanocrystalline oxide solid electrolytes for mixed potential NOx sensors can be found: there have been proposed structures based on nanostructured $\mathrm{CuO}$-doped $\mathrm{NiO}$ electrodes [98], nano-structured perovskites such as $\mathrm{LaFeO}_{3}$ [99], a more sensitive and stable version with $\mathrm{LaFeO}_{3}$-doped $\mathrm{Pt}[100]$, or thin films of $\mathrm{NiO}$ electrodes $[101,102]$.

4.3. Nanomaterials in Electrolytes. High temperature of operation (around $850 \mathrm{~K}$ ) in classical potentiometric ionconducting sensors is one of their main limitations. The aim of getting higher conductivities and lowering this temperature has stimulated the research on alternatives to traditional YSZ bulk ceramics. Although increasing the $\mathrm{Y}_{2} \mathrm{O}_{3}$ doping in $\mathrm{ZrO}_{2}$ can seem an easy way to enhance the ionic conductivity (due to the larger number of oxygen vacancies) of the ceramics, structural stability properties are affected. The main advantage of using bulk YSZ in oxygen sensors is that powders have high purity and uniform particle sizes, and this helps predicting the sensor properties as the grain size after sintering can be estimated. However, nanomaterials have provided some interesting improvements.

Several studies on synthesis of YSZ nanoparticles have been carried out, some of them with a relatively high dispersion in grin sizes [103-105]. By comparing conductivities and microstructure of single crystal, microcrystalline, and nanocrystalline YSZ, it was confirmed that the grain boundary resistance is the main contribution to the total resistance of nanocrystalline YSZ and other ceramic ionconductors [106-109]. Kosacki et al. [110] studied and modeled the total electrical conductivity in nanocrystalline YSZ thin films with controlled grain sizes in the range of
$1-400 \mathrm{~nm}$ and detected an enhancement of the activation energy for the ionic conductivity $(0.93 \mathrm{eV}$ in nanocrystalline YSZ in front of $1.23 \mathrm{eV}$ in microcrystalline YSZ). They were also found a slight increase of undesired electronic conductivity at very low oxygen partial pressures (below $\left.10^{-20} \mathrm{~atm}\right)$.

Another experiment with YSZ thin films was prepared [111] by epitaxially growing nanocrystalline $10 \mathrm{~mol} \% \mathrm{Y}_{2} \mathrm{O}_{3}-$ doped $\mathrm{ZrO}_{2}$ over a $\mathrm{MgO}$ substrate, producing YSZ thin films of different thickness. Differences in conductivity and activation energies were studied. Equivalent circuits fitted to measurements from impedance spectroscopy, along with models of conductivity in two-phase materials [112], were applied to separate the YSZ/MgO surface/interface and YSZ lattice conductivities. As a result, and according to the applied two-phase materials model, a nanoscale effect with exceptionally high ionic conductivity below $60 \mathrm{~nm}$ thickness was interpreted, with ionic conductivities 1000 times higher than in bulk YSZ and an activation energy of $0.45 \mathrm{eV}$.

García-Sánchez et al. [113] worked on nanostructured YSZ thin films for solid oxide fuel cells, although the results are perfectly extensible to electrochemical sensors. An activation energy of $0.79 \mathrm{eV}$ was achieved for ionconduction through the grain boundaries, increasing the total conductivity of the material up to $0.033 \mathrm{~S} / \mathrm{cm}$ at $923 \mathrm{~K}$. Nanostructured YSZ was obtained via ultrasonic spray pyrolysis, and relevant changes in grain sizes were observed in terms of the deposition time and temperature.

Zhu and Fan [114] focused on the consequences of ceramic sintering temperature when using YSZ nanoparticles. It was found that $8 \mathrm{~mol} \%$ YSZ nanopowders with an average grain size of $9 \mathrm{~nm}$ could be fully densified after $1300 \mathrm{~K}$ sintering for 24 hours, a temperature significantly lower than the usual $1650-1750 \mathrm{~K}$ for YSZ micrometric powder.

Nanostructured ion-conducting solid electrolytes have been claimed for possible oxygen sensing applications. Yadav and $\mathrm{Hu}$ [115] observed an order of magnitude enhancement in oxygen ion-conductivity in a $\mathrm{Ag} / \mathrm{YSZ} / \mathrm{Ag}$ cell exposed to two separate atmospheres containing oxygen and nitrogen. Conductivities of microstructured and nanostructured YSZ were extracted from impedance spectra and compared. Other patents have claimed similar nanostructured electrolytes for sensing devices [116-118], among other applications such as fuel cells or oxygen pumps.

Although it is not strictly a YSZ thin film for electrochemical gas sensors, it is interesting to comment the works of Dimitrov and Dushkin [119] on YSZ thin films with Pt nanoparticles for $\mathrm{O}_{2}$ resistive detection as an alternative method for oxygen sensing with nanomaterials. Thin films of pure YSZ and films of YSZ with Pt nanoparticles were prepared by spray pyrolysis and by dip coating of a substrate as well. The electric resistance was measured in the samples when exposed to several oxygen and nitrogen cycles. Although the pure YSZ sample showed a higher sensitivity to oxygen at $1075 \mathrm{~K}$, the Pt-YSZ sample had a faster response time and the response was relatively stable with time. A lower resistance in the case of the Pt-YSZ sample was attributed to the presence of the metal. 
Later, junctions consisting in YSZ in contact to YSZ with embedded Pt nanoparticles were prepared, observed, and tested as electrochemical sensors [120, 121]. Different platinum loadings were compared, and Nernstian responses were found when exposed to $0.9 \% \mathrm{O}_{2}$ in $\mathrm{N}_{2}$ for nanoparticle Pt loadings of $2.5 \% \mathrm{~mol}$ and $6.5 \% \mathrm{~mol}$ in YSZ.

\section{Conclusions}

Models of the behavior of YSZ-based potentiometric oxygen sensors have been reviewed. The classical models based on reaction rates and rates of adsorption of different gas species in the three-phase boundary sites are still useful to understand the general working principles of the sensors. Electric models fitted by impedance spectroscopy seem to be a powerful tool to extract information about phenomena in electrodes and electrolytes. The use of nanomaterials in these devices has shown promising improvements for modifying the mixed potentials to enhance gas selectivity, lowering the activation energies for ion-conduction, or avoiding current constriction in the electrode/electrolyte interfaces. However, they are still necessary more work to be done to implement the advantages of nanomaterials in commercial sensors, as problems with repeatability of measurements, dependence on experimental conditions, control of particle sizes, and spatially coherent nets of electron conducting contacts in the electrodes have to be solved.

\section{References}

[1] E. Ivers-Tiffèe, K. H. Härdtl, W. Menesklou, and J. Riegel, "Principles of solid state oxygen sensors for lean combustion gas control," Electrochimica Acta, vol. 47, no. 5, pp. 807-814, 2001.

[2] R. Moos, "A brief overview on automotive exhaust gas sensors based on electroceramics," International Journal of Applied Ceramic Technology, vol. 2, no. 5, pp. 401-413, 2005.

[3] W. J. Fleming, "Physical principles governing nonideal behavior of the zirconia oxygen sensor," Journal of the Electrochemical Society, vol. 124, pp. 21-28, 1977.

[4] J. Brettschneider, "Berechnung des luftverhältnisses lambda von luft-kraftstoff-gemischen und des einflusses von messfehlern auf lambda," Bosch Technische Berichte, vol. 6, pp. 177-186, 1979.

[5] J. Riegel, H. Neumann, and H. M. Wiedenmann, "Exhaust gas sensors for automotive emission control," Solid State Ionics, vol. 152-153, pp. 783-800, 2002.

[6] A. G. Mortimer and G. P. Reed, "Development of a robust electrochemical oxygen sensor," Sensors and Actuators B, vol. 24-25, no. 1-3, pp. 328-335, 1995.

[7] A. K. M. S. Chowdhury, S. A. Akbar, S. Kapileshwar, and J. R. Schorr, "A rugged oxygen gas sensor with solid reference for high temperature applications," Journal of the Electrochemical Society, vol. 148, pp. G91-G94, 2001.

[8] E. van Setten, T. M. Gür, D. H. A. Blank, J. C. Bravman, and M. R. Beasley, "Miniature Nernstian oxygen sensor for deposition and growth environments," Review of Scientific Instruments, vol. 73, no. 1, p. 156, 2002.

[9] E. Di Bartolomeo, N. Kaabbuathong, M. L. Grilli, and E. Traversa, "Planar electrochemical sensors based on tape-cast YSZ layers and oxide electrodes," Solid State Ionics, vol. 171, no. 3-4, pp. 173-181, 2004.
[10] H. Kaneko, T. Okamura, H. Taimatsu, Y. Matsuki, and H. Nishida, "Performance of a miniature zirconia oxygen sensor with a Pd-PdO internal reference," Sensors and Actuators B, pp. 331-334, 2005.

[11] M. Kleitz and E. Siebert, "Electrode reactions in potentiometric gas sensor," in Chemical Sensor Technology, T. Seiyama, Ed., vol. 2, pp. 151-171, Kodansha, Tokyo and Elsevier, Amsterdam, The Netherlands, 1989.

[12] M. Kleitz, E. Siebert, P. Fabry, and J. Fouletier, "Solid state electrochemical sensors," in Sensors: A Comprehensive Survey, T. Seiyama, Ed., vol. 2, pp. 341-428, VCH, Winheim, Germany, 1991.

[13] D. W. McKee, "Interaction of hydrogen and carbon monoxide on platinum group metals," Journal of Catalysis, vol. 8, no. 3, pp. 240-249, 1967.

[14] J. E. Anderson and Y. B. Graves, "Steady-state characteristics of oxygen concentration cell sensors subjected to nonequilibrium gas mixtures," Journal of the Electrochemical Society, vol. 128, no. 2, pp. 294-300, 1981.

[15] K. Saji, H. Kondo, T. Takeuchi, and I. Igarashi, "Voltage step characteristics of oxygen concentration cell sensors for nonequilibrium gas mixtures," Journal of the Electrochemical Society, vol. 135, pp. 1686-1691, 1988.

[16] A. D. Brailsford and E. M. Logothetis, "A steady-state diffusion model for solid-state gas sensors," Sensors and Actuators, vol. 7, no. 1, pp. 39-67, 1985.

[17] A. D. Brailsford, M. Yussouff, and E. M. Logothetis, "Theory of gas sensors," Sensors and Actuators B, vol. 13, no. 1-3, pp. 135-138, 1993.

[18] A. D. Brailsford, M. Yussouff, E. M. Logothetis, and M. Shane, "Steady-state model of a zirconia oxygen sensor in a simple gas mixture," Sensors and Actuators B, vol. 24-25, no. 1-3, pp. 362-365, 1995.

[19] A. D. Brailsford, M. Yussouff, and E. M. Logothetis, "Theory of gas sensors: response of an electrochemical sensor to multi-component gas mixtures," Sensors and Actuators B, vol. 34, no. 1-3, pp. 407-411, 1996.

[20] A. D. Brailsford, M. Yussouff, and E. M. Logothetis, "Steady state model of electrochemical gas sensors with multiple reactions," Sensors and Actuators B, vol. 35-36, no. 1-3, pp. 392-397, 1996.

[21] A. D. Brailsford, M. Yussouff, and E. M. Logothetis, "A firstprinciples model of the zirconia oxygen sensor," Sensors and Actuators B, vol. 44, no. 1-3, pp. 321-326, 1997.

[22] J. T. Woestman, A. D. Brailsford, M. Shane, and E. M. Logothetis, "A model of the transient response of masstransfer limited gas sensors," Sensors and Actuators B, vol. 45, no. 1, pp. 27-33, 1997.

[23] H. Fukunaga, M. Ihara, K. Sakaki, and K. Yamada, "The relationship between overpotential and the three phase boundary length," Solid State Ionics, vol. 86-88, pp. 11791185, 1996.

[24] M. Juhl, S. Primdahl, C. Manon, and M. Mogensen, "Performance/structure correlation for composite SOFC cathodes," Journal of Power Sources, vol. 61, no. 1-2, pp. 173-181, 1996.

[25] S. P. Yoon, S. W. Nam, J. Han, T. H. Lim, S. A. Hong, and S. H. Hyun, "Effect of electrode microstructure on gas-phase diffusion in solid oxide fuel cells," Solid State Ionics, vol. 166, no. 1-2, pp. 1-11, 2004.

[26] R. J. Aaberg, R. Tunold, and R. Odegard, "On the electrochemistry of metal-YSZ single contacts," Solid State Ionics, vol. 136-137, pp. 707-712, 2000. 
[27] S. Sridhar, V. Stancovski, and U. B. Pal, "Effect of oxygencontaining species on the impedance of the Pt/ YSZ interface," Solid State Ionics, vol. 100, no. 1-2, pp. 17-22, 1997.

[28] J. L. Hertz and H. L. Tuller, "Measurement and finite element modeling of triple phase boundary-related current constriction in YSZ," Solid State Ionics, vol. 178, no. 13-14, pp. 915-923, 2007.

[29] S. P. Yoon, S. W. Nam, S. G. Kim, S. A. Hong, and S. H. Hyun, "Characteristics of cathodic polarization at Pt/YSZ interface without the effect of electrode microstructure," Journal of Power Sources, vol. 115, no. 1, pp. 27-34, 2003.

[30] R. O'Hayre, D. Barnett, and F. B. Prinz, "The triple phase boundary: a mathematical model and experimental investigations for fuel cells," Journal of the Electrochemical Society, vol. 152, pp. 439-444, 2005.

[31] L. Bultel, P. Vernoux, F. Gaillard, C. Roux, and E. Siebert, "Electrochemical and catalytic properties of porous Pt-YSZ composites," Solid State Ionics, vol. 176, no. 7-8, pp. 793-801, 2005.

[32] T. Jacobsen, B. Zachau-Christiansen, L. Bay, and M. Juhl, "Hysteresis in the solid oxide fuel cell cathode reaction," Electrochimica Acta, vol. 46, no. 7, pp. 1019-1024, 2001.

[33] T. Jacobsen and L. Bay, "Thermal memory effects at the PtYSZ interface," Electrochimica Acta, vol. 47, pp. 2177-2181, 2002.

[34] A. Jaccoud, G. Foti, R. Wüthrich, H. Jotterand, and C. Comninellis, "Pt/YSZ microstructure and electrochemistry," Topics in Catalysis, vol. 44, no. 3, pp. 409-417, 2007.

[35] J. Nielsen and T. Jacobsen, "Three-phase boundary dynamics at Pt/YSZ microelectrodes," Solid State Ionics, vol. 178, pp. 1001-1009, 2007.

[36] E. L. Shoemaker, M. C. Vogt, F. J. Dudek, and T. Turner, "Gas microsensors using cyclic voltammetry with a cermet electrochemical cell," Sensors and Actuators B, vol. 42, no. 1, pp. 1-9, 1997.

[37] N. Miura, T. Raisen, G. Lu, and N. Yamazoe, "Highly selective CO sensor using stabilized zirconia and a couple of oxide electrodes," Sensors and Actuators B, vol. 47, no. 1-3, pp. 8491, 1998.

[38] N. Miura, G. Lu, and N. Yamazoe, "Progress in mixedpotential type devices based on solid electrolyte for sensing redox gases," Solid State Ionics, vol. 136-137, pp. 533-542, 2000.

[39] N. Miura, G. Lu, and N. Yamazoe, "High-temperature potentiometric/amperometric NOx sensors combining stabilized zirconia with mixed-metal oxide electrode," Sensors and Actuators B, vol. 52, no. 1-2, pp. 169-178, 1998.

[40] S. Zhuiykov, T. Nakano, A. Kunimoto, and N. Miura, "Potentiometric NOx sensor based on stabilized zirconia and $\mathrm{NiCr}_{2} \mathrm{O}_{4}$ sensing electrode operating at high temperatures," Electrochemistry Communications, vol. 3, no. 2, pp. 97-101, 2001.

[41] N. Miura, S. Zhuiykov, T. Ono, M. Hasei, and N. Yamazoe, "Mixed potential type sensor using stabilized zirconia and $\mathrm{ZnFe}_{2} \mathrm{O}_{4}$ sensing electrode for NOx detection at high temperature," Sensors and Actuators B, vol. 81, pp. 222-229, 2002.

[42] N. F. Szabo and P. K. Dutta, "Strategies for total NOx measurement with minimal $\mathrm{CO}$ interference utilizing a microporous zeolitic catalytic filter," Sensors and Actuators B, vol. 88 , no. 2 , pp. 168-177, 2003.

[43] S. Zhuiykov, "Mathematical modelling of YSZ-based potentiometric gas sensors with oxide sensing electrodes-part I: model of interactions of measuring gas with sensor," Sensors and Actuators B, vol. 119, no. 2, pp. 456-465, 2006.
[44] S. Zhuiykov, "Mathematical modelling of YSZ-based potentiometric gas sensors with oxide sensing electrodes-part II: complete and numerical models for analysis of sensor characteristics," Sensors and Actuators B, vol. 120, no. 2, pp. 645-656, 2007.

[45] H. Näfe, "How to check the validity of Nernst's law in a potentiometric solid electrolyte galvanic cell," Solid State Ionics, vol. 113-115, pp. 205-217, 1998.

[46] M. Er-Raki, M. Hasnaoui, A. Amahmid, and M. Bourich, "Soret driven thermosolutal convection in a shallow porous layer with a stress-free upper surface engineering computations," International Journal of Computationally Aided Engineering, vol. 22, no. 2, pp. 186-205, 2005.

[47] E. Mutoro, S. Günther, B. Luerßen, I. Valov, and J. Janek, "Electrode activation and degradation: morphology changes of platinum electrodes on YSZ during electrochemical polarisation," Solid State Ionics, vol. 179, no. 33-34, pp. 1835-1848, 2008.

[48] R. Ramamoorthy, S. A. Akbar, and P. K. Dutta, "Dependence of potentiometric oxygen sensing characteristics on the nature of electrodes," Sensors and Actuators B, vol. 113, no. 1, pp. 162-168, 2006.

[49] A. Jaccoud, C. Falgairette, G. Fóti, and C. Comninellis, "Charge storage in the $\mathrm{O}_{2}(\mathrm{~g}), \mathrm{Pt} / \mathrm{YSZ}$ system," Electrochimica Acta, vol. 52, no. 28, pp. 7927-7935, 2007.

[50] T. Wang, R. F. Novak, and R. E. Soltis, "A study of factors that influence zirconia/platinum interfacial impedance using equivalent circuit analysis," Sensors and Actuators B, vol. 77, no. 1-2, pp. 132-138, 2001.

[51] G. Reinhardt, R. Mayer, and M. Rösch, "Sensing small molecules with amperometric sensors," Solid State Ionics, vol. 150, no. 1-2, pp. 79-92, 2002.

[52] M. S. Ugorek, A comparison of microstructure and electrical properties of $8 \mathrm{~mol} \%$ yttria stabilized zirconia processed under conventional, microwave and fast-fire sintering techniques, Ph.D. thesis, 2004.

[53] L. Y. Woo, L. P. Martin, R. S. Glass, and R. J. Gorte, "Impedance characterization of a model Au/Yttria stabilized zirconia/au electrochemical cell in varying oxygen and $\mathrm{NO}_{\mathrm{x}}$ concentrations," Journal of the Electrochemical Society, vol. 154, pp. J129-J135, 2007.

[54] P. Costamagna, M. Panizza, G. Cerisola, and A. Barbucci, "Effect of composition on the performance of cermet electrodes. Experimental and theoretical approach," Electrochimica Acta, vol. 47, no. 7, pp. 1079-1089, 2002.

[55] W. F. Zhang, P. Schmidt-Zhang, and U. Guth, "Electrochemical studies on cells M/YSZ/Pt ( $\left.\mathrm{M}=\mathrm{Pt}, \mathrm{Pt}-\mathrm{Ga}_{2} \mathrm{O}_{3}\right)$ in $\mathrm{NO}, \mathrm{O}_{2}$ , $\mathrm{N}_{2}$ gas mixtures," Solid State Ionics, vol. 169, pp. 121-128, 2004.

[56] D. Eder and R. Kramer, "Impedance spectroscopy of reduced monoclic zirconia," Physical Chemistry Chemical Physics, vol. 8, no. 38, pp. 4476-4483, 2006.

[57] P. Ried, C. Lorenz, A. Brönstrup, et al., "Processing of YSZ screen printing pastes and the characterization of the electrolyte layers for anode supported SOFC," Journal of the European Ceramic Society, vol. 28, no. 9, pp. 1801-1808, 2008.

[58] J. T. S. Irvine, D. C. Sinclair, and A. R. West, "Electroceramics : characterization by impedance spectroscopy," Advanced Materials, vol. 2, no. 3, pp. 132-138, 2004.

[59] V. V. Kharton and F. M. B. Marques, "Interfacial effects in electrochemical cells for oxygen ionic conduction measurements: I. The e.m.f. method," Solid State Ionics, vol. 140, no. 3-4, pp. 381-394, 2001. 
[60] V. V. Kharton, F. M. B. Marques, E. V. Tsipis, et al., "Interfacial effects in electrochemical cells for oxygen ionic conduction measurements: III. Transference numbers vs. grain-boundary resistivity," Solid State Ionics, vol. 168, no. 12, pp. 137-151, 2004.

[61] S. H. Jensen, A. Hauch, P. V. Hendriksen, M. Mogensen, N. Bonanos, and T. Jacobsen, "A method to separate process contributions in impedance spectra by variation of test conditions," Journal of the Electrochemical Society, vol. 154, pp. B1325-B1330, 2007.

[62] H. Meng and P. K. Shen, "Novel Pt-free catalyst for oxygen electroreduction," Electrochemistry Communications, vol. 8, no. 4, pp. 588-594, 2006.

[63] J. R. Frade, V. V. Kharton, A. L. Shaula, and F. M. B. Marques, "Interfacial effects in potentiometric oxygen sensors: the role of transport properties and thickness of solid electrolyte ceramics," Sensor Letters, vol. 6, no. 3, pp. 370-380, 2008.

[64] G. Hsieh, T. O. Mason, and L. R. Pederson, "Experimental limitations in impedance spectroscopy-part I: simulation of reference electrode artifacts in three-point measurements," Solid State Ionics, vol. 91, no. 3-4, pp. 191-201, 1996.

[65] G. Hsieh, T. O. Mason, and L. R. Pederson, "Experimental limitations in impedance spectroscopy-part II: electrode artifacts in three-point measurements on Pt/YSZ," Solid State Ionics, vol. 91, no. 3-4, pp. 203-212, 1996.

[66] R. Radhakrishnan, A. V. Virkar, S. C. Singhal, G. C. Dunham, and O. A. Marina, "Design, fabrication and characterization of a miniaturized series-connected potentiometric oxygen sensor," Sensors and Actuators B, vol. 105, no. 2, pp. 312-321, 2005.

[67] M. Zhou and A. Ahmad, "Synthesis, processing and characterization of calcia-stabilized zirconia solid electrolytes for oxygen sensing applications," Materials Research Bulletin, vol. 41, no. 4, pp. 690-696, 2006.

[68] E. Caproni, F. M. S. Carvalho, and R. Muccillo, "Development of zirconia-magnesia/zirconia-yttria composite solid electrolytes," Solid State Ionics, vol. 179, no. 27-32, pp. 1652 1654, 2008.

[69] N. Balakrishnan, T. Takeuch, K. Nomura, H. Kageyama, and Y. Takeda, "Aging effect of $8 \mathrm{~mol} \%$ YSZ ceramics with different microstructures," Journal of the Electrochemical Society, vol. 151, pp. 1286-1291, 2004.

[70] M. Ghatee, M. H. Shariat, and J. T. S. Irvine, "Investigation of electrical and mechanical properties of $3 \mathrm{YSZ} / 8 \mathrm{YSZ}$ composite electrolytes," Solid State Ionics, vol. 180, no. 1, pp. 57-62, 2009.

[71] M. Mogensen, D. Lybye, N. Bonanos, P. V. Hendriksen, and F. W. Poulsen, "Factors controlling the oxide ion conductivity of fluorite and perovskite structured oxides," Solid State Ionics, vol. 174, no. 1-4, pp. 279-286, 2004.

[72] X. Guo and R. Waser, "Electrical properties of the grain boundaries of oxygen ion conductors: acceptor-doped zirconia and ceria," Progress in Materials Science, vol. 51, no. 2, pp. 151-210, 2006.

[73] W. Göpel, "Nanostructured sensors for molecular recognition," Philosophical Transactions of the Royal Society A, vol. 353, pp. 333-354, 1995.

[74] W. Göpel, "Ultimate limits in the miniaturization of chemical sensors," Sensors and Actuators A, vol. 56, pp. 83-102, 1996.

[75] W. Göpel, "Chemical analysis and sensorics with microstructured devices," Mikrochimica Acta, vol. 125, pp. 179-196, 1997.
[76] X. Huang and D. Y. Choi, "Chemical sensors based on nanostructured materials," Sensors and Actuators B, vol. 122, pp. 659-671, 2007.

[77] T. Kimura and T. Goto, "Ir-YSZ nano-composite electrodes for oxygen sensors," Surface \& Coatings Technology, vol. 198, pp. 36-39, 2005.

[78] A. M. Torres-Huerta, J. R. Vargas-García, and M. A. Domínguez-Crespo, "Preparation and characterization of $\mathrm{IrO}_{2}$-YSZ nanocomposite electrodes by MOCVD," Solid State Ionics, vol. 178, no. 29-30, pp. 1608-1616, 2007.

[79] A. Barbucci, R. Bozzo, G. Cerisola, and P. Costamagna, "Characterisation of SOFC composite cathodes using electrochemical impedance spectroscopy. Analysis of Pt/YSZ and LSM/YSZ electrodes," Electrochimica Acta, vol. 47, pp. 21832188, 2002.

[80] X. Wang, H. Huang, T. Holme, X. Tian, and F. B. Prinz, "Thermal stabilities of nanoporous metallic electrodes at elevated temperatures," Journal of Power Sources, vol. 175, no. 1, pp. 75-81, 2008.

[81] K. Gong, Y. Yan, M. Zhang, L. Su, S. Xiong, and L. Mao, "Electrochemistry and electroanalytical applications of carbon nanotubes: a review," Analytical Sciences, vol. 21, no. 12, pp. 1383-1393, 2005.

[82] J. Wang, G. Chen, M. Wang, and M. P. Chatrathi, "Carbonnanotube/copper composite electrodes for capillary electrophoresis microchip detection of carbohydrates," Analyst, vol. 129, no. 6, pp. 512-515, 2004.

[83] S. Hrapovic, Y. Liu, K. B. Male, and J. H. T. Luong, "Electrochemical biosensing platforms using platinum nanoparticles and carbon nanotubes," Analytical Chemistry, vol. 76, no. 4, pp. 1083-1088, 2004.

[84] P. J. Britto, K. S. V. Santhanam, A. Rubio, J. A. Alonso, and P. M. Ajayan, "Improved charge transfer at carbon nanotube electrodes," Advanced Materials, vol. 11, no. 2, pp. 154-157, 1999.

[85] P. G. Collins, K. Bradley, M. Ishigami, and A. Zettl, "Extreme oxygen sensitivity of electronic properties of carbon nanotubes," Science, vol. 287, no. 5459, pp. 1801-1804, 2000.

[86] U. Cvelbar and M. Mozetič, "Behaviour of oxygen atoms near the surface of nanostructured $\mathrm{Nb}_{2} \mathrm{O}_{5}$," Journal of Applied Physics D, vol. 40, no. 8, pp. 2300-2303, 2007.

[87] N. Wu, M. Zhao, J. G. Zheng, et al., "Porous CuO-ZnO nanocomposite for sensing electrode of high-temperature CO solid-state electrochemical sensor," Nanotechnology, vol. 16, no. 12, pp. 2878-2881, 2005.

[88] X. Li and G. M. Kale, "Novel nanosized ITO electrode for mixed potential gas sensors," Electrochemistry Solid State Letters, vol. 8, pp. 27-30, 2005.

[89] X. Li and G. M. Kale, "Influence of thickness of ITO sensing electrode film on sensing performance of planar mixed potential CO sensor," Sensors and Actuators B, vol. 120, no. 1, pp. 150-155, 2006.

[90] X. Li and G. M. Kale, "Planar mixed-potential CO sensor utilizing novel BLIO and ITO interface," Electrochemistry Solid State Letters, vol. 9, pp. 12-15, 2005.

[91] X. Li and G. M. Kale, "Influence of sensing electrode and electrolyte on performance of potentiometric mixedpotential gas sensors," Sensors and Actuators B, vol. 123, no. 1, pp. 254-261, 2007.

[92] V. V. Plashnitsa, P. Elumalai, and N. Miura, "Sensitive and selective zirconia-based $\mathrm{NO}_{2}$ sensor using gold nanoparticle coatings as sensing electrodes," Journal of the Electrochemical Society, vol. 155, pp. 301-306, 2008. 
[93] J. Zosel, D. Tuchtenhagen, K. Ahlborn, and U. Gith, "Mixed potential gas sensor with short response time," Sensors and Actuators B, vol. 130, no. 1, pp. 326-329, 2008.

[94] S. Thiemann, R. Hartung, H. Wulff, et al., "Modified $\mathrm{Au} / Y S Z$ electrodes - preparation, characterization and electrode behaviour at higher temperatures," Solid State Ionics, vol. 86-88, pp. 873-876, 1996.

[95] L. Chevallier, E. Di Bartolomeo, M. L. Grilli, et al., "Nonnernstian planar sensors based on YSZ with a $\mathrm{Nb}_{2} \mathrm{O}_{5}$ electrode," Sensors and Actuators B, vol. 129, no. 2, pp. 591597, 2008.

[96] T. Hibino, S. Wang, S. Kakimoto, and M. Sano, "Detection of propylene under oxidizing conditions using zirconia-based potentiometric sensor," Sensors and Actuators B, vol. 50, 1998.

[97] J. Zosel, K. Ahlborn, R. Müller, D. Westphal, V. Vashook, and U. Guth, "Selectivity of HC-sensitive electrode materials for mixed potential gas sensors," Solid State Ionics, vol. 169, pp. 115-119, 2004.

[98] V. V. Plashnitsa, T. Ueda, and N. Miura, "Improvement of $\mathrm{NO}_{2}$ a sensing performances by an additional second component to the nano-structured $\mathrm{NiO}$ sensing electrode of a YSZ-based mixed-potential-type sensor," International Journal of Applied Ceramic Technology, vol. 3, no. 2, pp. 127133, 2007.

[99] E. Di Bartolomeo, N. Kaabbuathong, A. D’Epifanio, et al., "Nano-structured perovskite oxide electrodes for planar electrochemical sensors using tape casted YSZ layers," Journal of the European Ceramic Society, vol. 24, no. 6, pp. 1187-1190, 2004.

[100] J. W. Yoon, M. L. Grilli, E. D. Bartolomeo, et al., "The $\mathrm{NO}_{2}$ response of solid electrolyte sensors made using nano-sized $\mathrm{LaFeO}_{3}$ electrodes," Sensors and Actuators B, vol. 76, pp. 483488, 2001.

[101] V. V. Plashnitsa, T. Ueda, P. Elumalai, and N. Miura, " $\mathrm{NO}_{2}$ sensing performances of planar sensor using stabilized zirconia and thin-NiO sensing electrode," Sensors and Actuators B, vol. 130, no. 1, pp. 231-239, 2008.

[102] V. V. Plashnitsa, T. Ueda, P. Elumalai, T. Kawaguchi, and N. Miura, "Zirconia-based planar $\mathrm{NO}_{2}$ sensor using ultrathin $\mathrm{NiO}$ or laminated $\mathrm{NiO}-\mathrm{Au}$ sensing electrode," Ionics, vol. 14, no. 1, pp. 15-25, 2008.

[103] S. C. Zhang, G. L. Messing, and M. Borden, "Synthesis of solid, spherical zirconia particles by spray pyrolysis," Journal of the American Ceramics Society, vol. 73, pp. 61-67, 1990.

[104] Y. Q. Xie, "Preparation of ultrafine zirconia particles," Journal of the American Ceramic Society, vol. 82, pp. 768-770, 1999.

[105] R. Jossen, R. Müller, S. E. Pratsinis, M. Watson, and M. K. Akhtar, "Morphology and composition of spray-flame-made yttria-stabilized zirconia nanoparticles," Nanotechnology, vol. 16, pp. 609-617, 2005.

[106] I. Kosacki, B. Gorman, and H. U. Anderson, "Microstructure and electrical conductivity in nanocrystalline oxide thin films," in Ionic and Mixed Conducting Ceramics, T. A. Ramanarayanan, Ed., vol. 3, pp. 631-642, Electrochemical Society, Pennington, NJ, USA, 1998, PV 97-24.

[107] Y. M. Chiang, E. B. Lavik, I. Kosacki, H. L. Tuller, and J. Y. Ying, "Defect and transport properties of nanocrystalline $\mathrm{CeO}_{2-\mathrm{x}}$," Applied Physics Letters, vol. 69, no. 2, pp. 185-187, 1996.

[108] I. Kosacki and H. U. Anderson, "The transport properties of nanocrystalline $\mathrm{SrCe}_{0.95} \mathrm{Yb}_{0.05} \mathrm{O}_{3}$ thin films," Applied Physics Letters, vol. 69, no. 27, pp. 4171-4173, 1996.

[109] Y. M. Chiang, E. B. Lavik, I. Kosacki, H. L. Tuller, and J. Y. Ying, "Nonstoichiometry and electrical conductivity of nanocrystalline $\mathrm{CeO}_{2-x}$," Journal of Electroceramics, vol. 1, no. 1, pp. 7-14, 1997.

[110] I. Kosacki, T. Suzuki, V. Petrovsky, and H. U. Anderson, "Electrical conductivity of nanocrystalline ceria and zirconia thin films," Solid State Ionics, vol. 136-137, pp. 1225-1233, 2000.

[111] I. Kosacki, C. M. Rouleau, P. F. Becher, J. Bentley, and D. H. Lowndes, "Nanoscale effects on the ionic conductivity in highly textured YSZ thin films," Solid State Ionics, vol. 176, no. 13-14, pp. 1319-1326, 2005.

[112] A. F. Uvarov, "Estimation of composities conductivity using a general mixing rule," Solid State Ionics, vol. 136-137, pp. 1267-1272, 2000.

[113] M. F. García-Sánchez, J. Peña, A. Ortiz, et al., "Nanostructured YSZ thin films for solid oxide fuel cells deposited by ultrasonic spray pyrolysis," Solid State Ionics, vol. 179, no. 78, pp. 243-249, 2008.

[114] Q. Zhu and B. Fan, "Low temperature sintering of 8YSZ electrolyte film for intermediate temperature solid oxide fuel cells," Solid State Ionics, vol. 176, no. 9-10, pp. 889-894, 2005.

[115] T. Yadav and H. Hu, "Nanostructured solid electrolytes and devices,” US patent no. 6387560, 1999.

[116] T. Yadav and H. Hu, "Nanostructured powders and related nanotechnology," US patent no. 2004/0005485, 2004.

[117] W. N. Lawless, "Ceramic fuel cell," US patent no. 6372375 , 2002.

[118] M. M. Seabaugh, S. L. Swartz, W. J. Dawson, and B. E. McCormick, "Ceramic electrolyte coating and methods," US patent no. 2005/0026017, 2005.

[119] D. T. Dimitrov and C. D. Dushkin, "Oxygen detection using yttria-stabilized zirconia thin films doped with platinum," Central European Journal of Chemistry, vol. 3, no. 4, pp. 605621, 2005.

[120] D. T. Dimitrov, S. Y. Anastosova, and C. D. Dushkin, “Oxygen sensing junctions based on yttria-stabilized zirconia with platinum nanoparticles," Review of Scientific Instruments, vol. 77, Article ID 056108, 2006.

[121] D. T. Dimitrov, C. D. Dushkin, N. L. Petrova, et al., "Oxygen detection using junctions based on thin films of yttriastabilized zirconia doped with platinum nanoparticles and pure yttria-stabilized zirconia," Sensors and Actuators A, vol. 137, no. 1, pp. 86-95, 2007. 

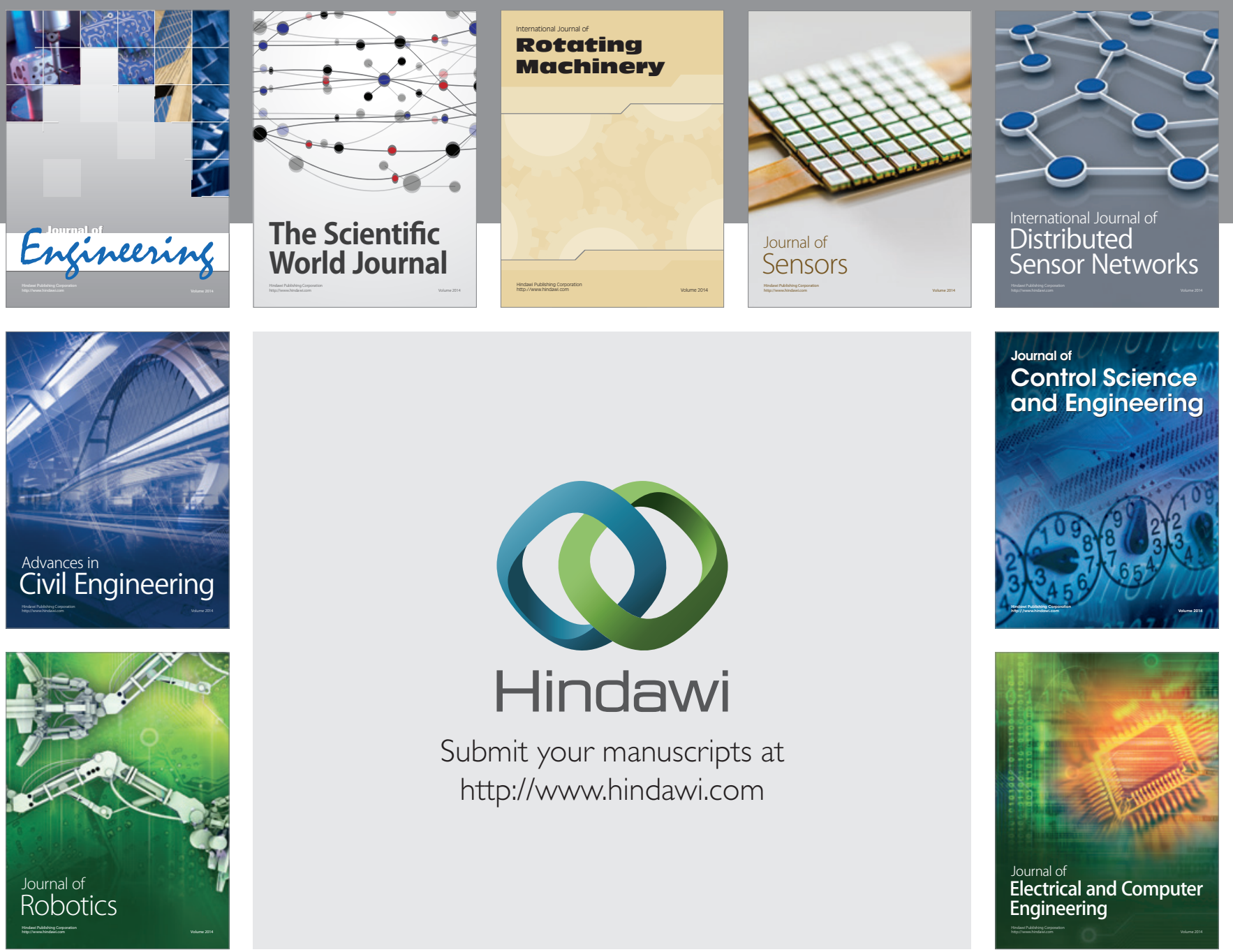

Submit your manuscripts at

http://www.hindawi.com
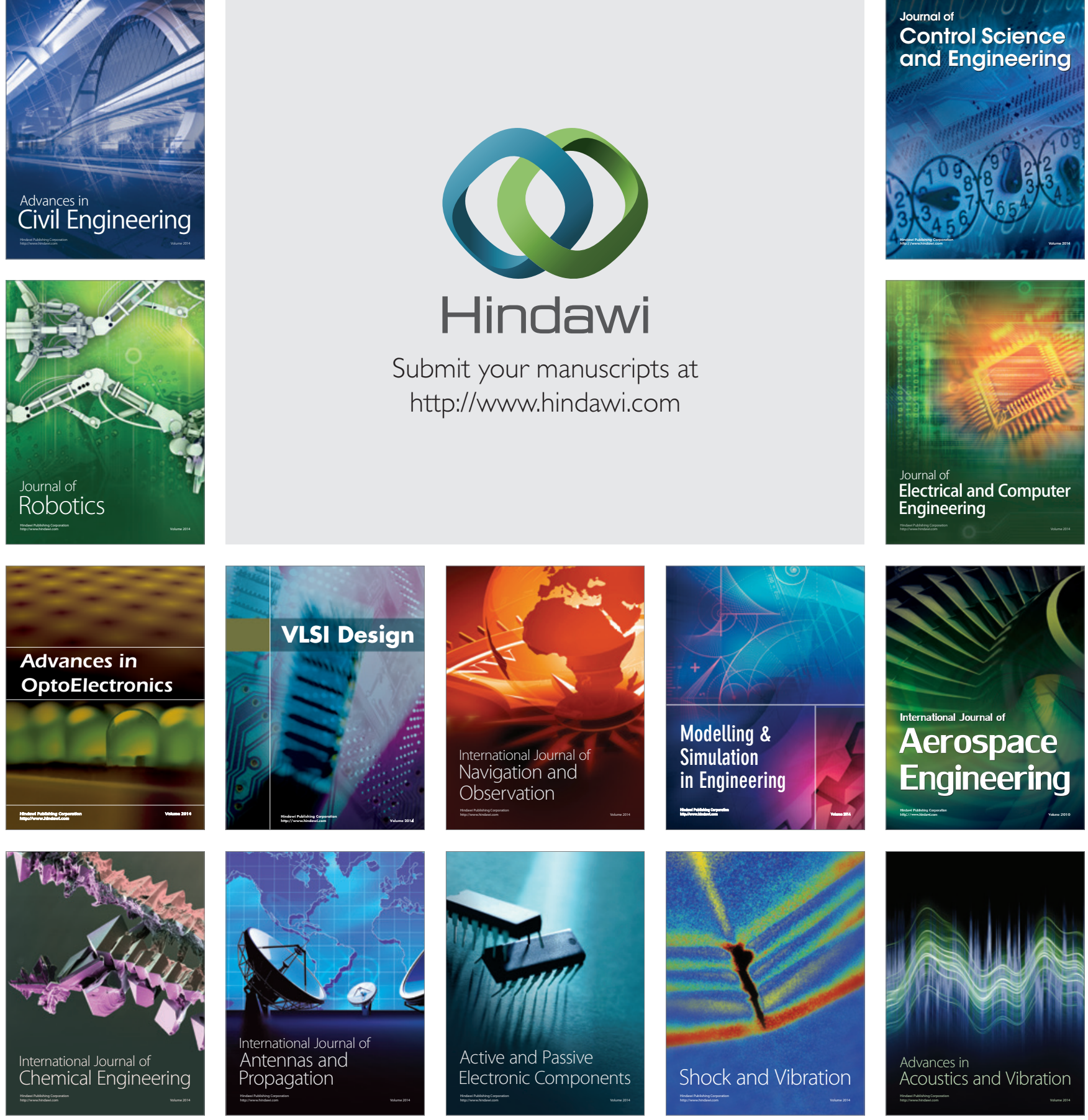